RAPID COMMUNICATION

\title{
Ghrelin elicits a marked stimulatory effect on GH secretion in freely-moving rats
}

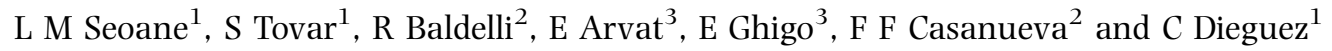 \\ Departments of ${ }^{1}$ Physiology and ${ }^{2}$ Medicine, University of Santiago, Santiago de Compostela, Spain and ${ }^{3}$ Dept of Endocrinology, University of Torino, \\ Torino, Italy \\ (Correspondence should be addressed to C Dieguez, Faculty of Medicine, Santiago de Compostela, E-15700, Spain; Email: fscadigo@usc.es)
}

\begin{abstract}
Ghrelin is a growth hormone-releasing acylated peptide from stomach. The purified peptide consist of 28 amino acids in which the serine 3 residue is n-octanoylated. Ghrelin has been reported to increase in vitro $\mathrm{GH}$ secretion as well as in vivo plasma $\mathrm{GH}$ levels in pentobarbital anaesthetized rats. The aim of this work was to characterize the stimulatory effect of Ghrelin on in vivo GH secretion in freely-moving rats. Furthermore, we compare the effect of Ghrelin with GHRH.

In addition to vehicle, we administered different doses of Ghrelin $(3 \mathrm{nmol} / \mathrm{Kg}, 12 \mathrm{nmol} / \mathrm{Kg}$ and $60 \mathrm{nmol} / \mathrm{Kg}$ ); GHRH $(3 \mathrm{nmol} / \mathrm{Kg}$ and $12 \mathrm{nmol} / \mathrm{kg})$. Plasma $\mathrm{GH}$ levels were measured in blood samples taken at $5,10,15,20,30$ and $45 \mathrm{~min}$ after their administration as an i.v. bolus at $0 \mathrm{~min}$.

Administration of Ghrelin led to an increase in plasma GH levels at all time-points tested (5, 10, 15, 20 and $30 \mathrm{~min}, P<0.01$; and $45 \mathrm{~min}, P<0.05)$ in comparison to control untreated rats. A maximal stimulatory effect on plasma GH was observed following administration of $12 \mathrm{nmol} / \mathrm{Kg}$ of Ghrelin, the effect being similar to the one obtained with $60 \mathrm{nmol} / \mathrm{Kg}$ in terms of both AUC and mean peak GH levels. At the dose of $3 \mathrm{nmol} / \mathrm{Kg}$ GHRH and Ghrelin exhibited a similar stimulatory effect in term of both, AUC and mean peak GH levels. However following administration of a dose of $12 \mathrm{nmol} /$ $\mathrm{Kg}$, the effect of Ghrelin was much greater than the same dose of GHRH in terms of both AUC and mean peak $\mathrm{GH}$ levels.

In summary, this study provides the first evidences that Ghrelin exert a marked stimulatory effect in plasma GH levels in freely-moving rats and provides further evidences that Ghrelin may play an important role in the physiological control of $\mathrm{GH}$ secretion.
\end{abstract}

European Journal of Endocrinology 143 R7-R9

\section{Introduction}

Growth hormone secretagogues (GHSs) are artificial compounds which release GH in all species tested so far. Up to now, these molecules mimicked an unknown endogenous factor that activates the GHS-receptor (1$3)$. The earlier cloning of GHS-R suggested that an endogenous ligand for this receptor might exist (4). Indeed, after intensive searches by different groups, the isolation of an endogenous ligand of the GHS-receptor, named Ghrelin (5) was recently reported. The purified ligand was found to be a peptide of 28 amino acids, in which the serine 3 residue, was n-octanoylated. This peptide have been shown to exert a very potent and specific GH-releasing activity in vitro as well as in vivo in pentobarbital anaesthetized rats. Taking into account that it is secreted prevalently from the stomach and that Ghrelin circulates in normal subjects at considerable plasma concentrations it has been postulated that this molecule is secreted from the stomach, circulating in the blood stream to stimulates GH secretion by the somatotrophs (5). More recently a second endogenous ligand for the GHS-R named des-Gln14-ghrelin, has been purified and characterized (6). Its biological activity and sequence is identical to Ghrelin except for one glutamine in position 14 .

It is well known that in vivo GH secretion is pulsatile. The male rat exhibit a pattern of GH secretion consisting of pulses of high amplitude, on average one every three hours, with almost undetectable throughs in between $(7,8)$. The aim of this paper was to assess the stimulatory of Ghrelin on in vivo $\mathrm{GH}$ secretion in the rat. To this end we have used freely-moving rats since in this experimental model the physiological regulatory mechanisms are fully operating. Furthermore, we assessed in the same experiments the stimulatory effect of GHRH which is considered to play a dominant regulatory role on $\mathrm{GH}$ synthesis and secretion.

\section{Materials and methods}

Adult male Sprague-Dawley rats $(200-250 \mathrm{~g})$ were kept with a ratio of $12 \mathrm{~h}$ light:12 h darkness in a temperature- and humidity-controlled room. Chronic 

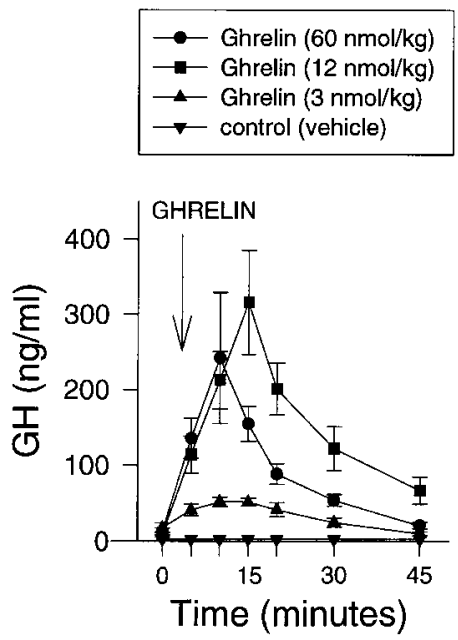

- GHRH (12 $\mathrm{nmol} / \mathrm{kg})$

- GHRH (3 nmol/kg)

- control (vehicle)

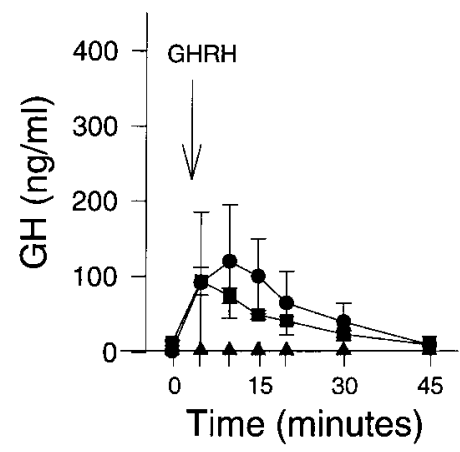

Figure 1 Mean+S.E.M. plasma GH levels after the administration (i.v.) of vehicle (control), Ghrelin and GHRH in adult male freely-moving rats ( $n=7-17$ rats/group). intracardiac cannulae were implanted under ketaminexylazine anaesthesia, as previously described (9). After surgery, the animals were placed directly in isolation test chambers for 5 days and were given free acess to regular Purina rat chow and tap water. Thereafter the animals were allowed to feed ad libitum. On the day of the experiment, blood samples $(0.3 \mathrm{ml})$ were withdrawn at the appropriate times. The animals $(n=6-10$ rats/group) received either vehicle, GHRH (Geref, Serono, Spain) or Ghrelin (Peninsula, U.K.) as an i.v. bolus.

Plasma GH concentrations were determined by double antibody RIA using materials supplied by the NHPP as described previously (10). Values are expressed in terms of the $\mathrm{GH}$ reference preparation (GH-RP-2). The intra- and interassay coefficients of variation were $2.4 \%$ and $4.8 \%$ respectively.

Data are expressed as mean + s.e.m. Comparison between the different groups was assessed by the Mann-Whitney test.

\section{Results}

Administration of Ghrelin led to an increase in plasma $\mathrm{GH}$ levels at al time-point tested $(5,10,15,20$ and $30 \mathrm{~min}, P<0.01$; and $45 \mathrm{~min}, P<0.05$ ) in comparison to control untreated rats. A maximal stimulatory effect on plasma GH was observed following administration of $12 \mathrm{nmol} / \mathrm{Kg}$ of Ghrelin, the effect being similar to the one obtained with $60 \mathrm{nmol} / \mathrm{Kg}$ in terms of both AUC and mean peak GH levels (Figs 1 and 2).

Administration of GHRH, either $3 \mathrm{nmol} / \mathrm{kg}$ or $12 \mathrm{nmol} / \mathrm{Kg}$ also led to a clear increase in plasma $\mathrm{GH}$ levels, at 5, 10, 15, 20 and $30 \mathrm{~min}(P<0.01)$ in comparison to control rats. At the dose of $3 \mathrm{nmol} / \mathrm{Kg}$ GHRH and Ghrelin exhibited a similar stimulatory effect in term of both AUC and mean peak GH levels. However following administration of a dose of
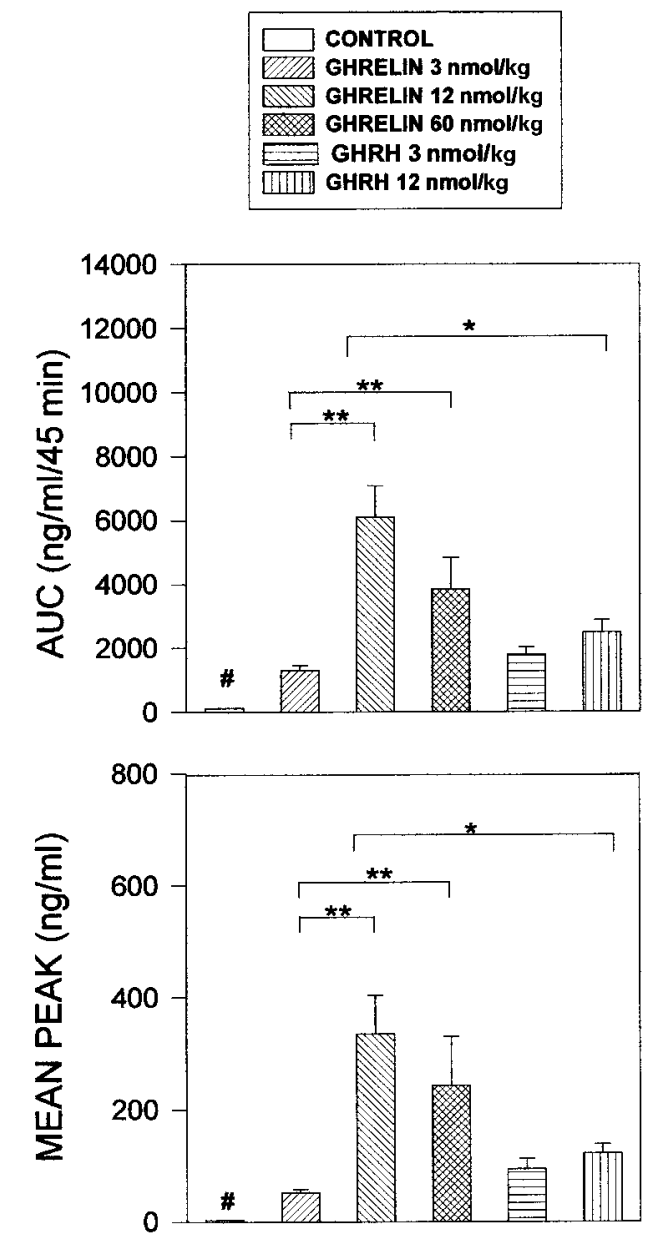

Figure 2 Area under curve (AUC) and mean peak $\mathrm{GH}$ levels following the administration of vehicle (control), Ghrelin and GHRH in adult male freely-moving rats. ${ }^{\star} P<0.05,{ }^{* \star} P<0.01, \# P<0.01$ (control rats versus rats treated with any dose of Ghrelin or $\mathrm{GHRH}$ ). 
$12 \mathrm{nmol} / \mathrm{Kg}$, the effect of Ghrelin was much greater than the same dose of GHRH in terms of both AUC and mean peak GH levels.

\section{Discussion}

The isolation of Ghrelin is one of the most important breakthroughs in the understanding of the regulatory mechanisms involved in the neuroregulation of $\mathrm{GH}$ secretion for several reasons (11). It gives definitive proof of the existence of a GHS-GHS-receptor signaling system in the control of $\mathrm{GH}$ secretion. Although for many years it became dogma that GH secretion by the anterior pituitary gland was the net result of the antagonistic actions of GHRH and somatostatin, a new physiological model of the regulation of $\mathrm{GH}$ secretion involving GHRH, somatostatin and Ghrelin must now be developed. It opens up the possibility of gaining a greater insight into the physiopathological mechanisms involved in the alterations of somatotroph cell function and somatic growth. Finally, it will allow the development of new agonist and antagonist compounds that may well be useful in the treatment of different disease states.

Previous data have shown that Ghrelin is a potent GH secretagogue both in vivo and in vitro (5). However, the in vivo GH-releasing activity of Ghrelin was tested in pentobarbital-anaesthetized rats, and this experimental model is limited by the fact that pentobarbital inhibits hypothalamic somatostatin release. In the present study we therefore decide to assess the effect of Ghrelin in freely-moving rats, a model that allows all the regulatory mechanisms to be in opereration $(7,8)$.

We found that Ghrelin elicits a clear-cut increase in plasma GH levels at all the doses tested. At the lowest dose tested $(3 \mathrm{nmol} / \mathrm{Kg})$ it exhibited a similar $\mathrm{GH}$ releasing activity than GHRH. However, the maximal stimulatory effect exerted by Ghrelin was 2 to 3 times greater than GHRH in terms of both AUC and mean peak $\mathrm{GH}$ levels. This is a very interesting finding since it shows that in vivo Ghrelin is a more potent $\mathrm{GH}$ releaser than GHRH, which is in contrast to the their in vitro effects where the opposite was described (5). Nevertheless, it should be noted that it is well established that GHRH is needed for somatotroph cell proliferation, and that $\mathrm{GH}$ synthesis and $\mathrm{GH}$ secretion elicited by most $\mathrm{GH}$ stimuli, including synthetic compounds that activate the GHS-receptor, are absent after administration of a GHRH-antagonist as well as after passive immunization with anti-GHRH antiserum $(12,13)$. Although, direct evidences is lacking at present, it could be postulated that while GHRH may well play a pleiotropic role on somatotroph cell function, GH secretion will be dependent on the antagonistic effects exerted by Ghrelin and somatostatin. Future studies assessing Ghrelin, GHRH and somatostatin levels in portal blood vessels and their relationship to $\mathrm{GH}$ pulses should answer this question.
In summary, this study provides the first evidences that Ghrelin exert a marked stimulatory effect in plasma GH levels in freely-moving rats and provides further evidences that Ghrelin may play an important role in the physiological control of $\mathrm{GH}$ secretion.

\section{Acknowledgements}

This study was supported by grants from the Fondo de Investigaciòn Sanitaria, Spanish Ministry of Health and the Xunta de Galicia.

\section{References}

1 Korbonits M \& Grossman AB. Growth hormone-releasing peptide and its analogues: novel stimuli to growth hormone release. Trends in Endocrinology and Metabolism 19956 43-49.

2 Ghigo E, Arvat E, Muccioli G \& Camanni F. Growth hormonereleasing peptides. European Journal of Endocrinology 1997136 445-460.

3 Casanueva FF \& Dieguez C. Growth hormone secretagogues: Physiological role and clinical utility. Trends in Endocrinology and Metabolism 199910 30-38.

4 Smith RG, Van der Ploeg LHT \& Howard AD et al. Peptidomimetic regulation of growth hormone secretion. Endocrine Reviews $199718621-645$.

5 Kojima M, Hosoda H, Date Y, Nakazato M, Matsuo H \& Kangawa K. Ghrelin is a growth hormone-releasing acylated peptide from stomach. Nature $1999 \mathbf{4 0 2} 656-660$.

6 Hosoda H, Kojima M, Matsuo H \& Kangawa K. Purification and characterization of rat des-Gln14-ghrelin, a second endogenous ligand of the growth hormone secretagogue-receptor. Journal of Biological Chemistry 2000275 21995-22000.

7 Tannenbaum GS \& Ling N. The interrelationship between growth hormone $(\mathrm{GH})$-releasing factor and somatostatin in the generation of the ultradian rhythm of GH secretion. Endocrinology 1984 115 1952-1957.

8 Oliver C, Dadoun F, Briard N, Guillaume V, Sauze N, Grino M \& Dutour A. Mechanisms of actions of growth hormone-releasing peptides and their analogues in vivo. In Growth hormone secretagogues, pp 91-104. Eds E Ghigo, M Boghen, FF Casanueva \& C Dieguez. Amsterdam: Elsevier, 1999.

9 Mallo F, Lamas JA, Casanueva FF \& Dieguez C. Effect of retinoic acid deficiency on in vivo and in vitro $\mathrm{GH}$ responses to $\mathrm{GHRH}$ in male rats. Neuroendocrinology $199255642-647$.

10 Carro E, Señaris R, Seoane LM, Frohman L, Arimura A, Casanueva FF \& Dieguez C. Role of growth hormone $(\mathrm{GH})$ releasing hormone and somatostatin on leptin-induced $\mathrm{GH}$ secretion. Neuroendocrinology 199969 3-10.

11 Dieguez C \& Casanueva FF. Ghrelin: a step forward in the understanding of somatotroph cell function and growth regulation. European Journal of Endocrinology $2000142413-417$.

12 Frohman LA \& Kineman RD. Growth hormone-releasing hormone: discovery, regulation and actions. In Handbook of Physiology: Hormonal control of growth, pp 189-221. Ed. J Kostyo. New York: Oxford University Press, 1999.

13 Dimaraki EV \& Barkan AL. Regulation of growth hormone $(\mathrm{GH})$ pulsatility in humans. In Growth hormone secretagogues, pp 115138. Eds E Ghigo, M Boghen, FF Casanueva \& C Dieguez. Amsterdam: Elsevier, 1999.

Received 26 September 2000

Accepted 29 September 2000 